\title{
REPRESENTAÇÕES COLETIVAS SOBRE A SELEÇÃO PERUANA DE FUTEBOL NA COPA DO MUNDO DA ARGENTINA - DE GRATA SURPRESA A POLEMICO "VILÃO"
}

\author{
COLECTIVE REPRESENTATIONS ABOUT PERUVIAN NATIONAL TEAM IN \\ THE WORLD CUP OF ARGENTINA - FROM AT THANKFUL SURPRISE TO A \\ CONTROVERSIAL "VILLAIN"
}

\begin{abstract}
Alvaro Vicente do Cabo*
RESUMO

O presente artigo tem como objetivo principal identificar representações coletivas sobre a campanha da seleção peruana de futebol na Copa do Mundo realizada na Argentina em 1978 em veículos da imprensa brasileira e argentina. Desde a surpresa em torno da boa campanha realizada pelos peruanos na primeira fase do torneio até a polêmica goleada de 6x0 que classificou os argentinos para a final, a equipe peruana se foi importante personagem no evento e ocupou um grande espaço midiático nos periódicos pesquisados.
\end{abstract}

Palavras-chave: Copa do Mudo; futebol peruano; representações coletivas, imprensa.

\begin{abstract}
This article aims to identifie the colective representations about the peruvian national team campaign at Word Cup hosted in Argentina in 1978, troughout vehicles of brazilian and argentine press. Since being a good surprise in the first round of the tournament until the controversy trashed $6 \mathrm{x} 0$ that qualified the argentines to the final, the peruvian team was an important character at the event and occupied a big media space at the researched journals and magazines.
\end{abstract}

Keywords: World Cop; peruvian soccer; collective representations; press.

"Doutor em História PPGHC/UFRJ, Mestre em Comunicação Social PPGCOM UERJ, Bacharel em História UFRJ, Direito (UNESA). Professor docente UCAM (Cândido Mendes) e Prefeitura RJ. Membro dos grupos de pesquisa SPORT/UFRJ e LEME/UERJ. 


\section{INTRODUÇÃO}

O futebol peruano não possui o mesmo prestígio das tradicionais potências futebolísticas da América do Sul como Brasil, Argentina, Uruguai e até mesmo algumas gerações chilenas ou paraguaias, devido, provavelmente, ao fraco desempenho internacional.

A origem histórica do futebol no país tem uma genealogia oficial semelhante às tradicionais hipóteses dos outros países sul-americanos. Trazido por imigrantes ingleses, marinheiros ou membros das elites peruanas que estudaram na Europa, acabou se popularizando com a propagação do esporte nas escolas e fábricas. Segundo Vidal:

En sus orígenes el fútbol en el Peru estuvo asociado a pobladores de elite. El historiador Gerardo Alvarez, en su tésis de licenciatura por la Universidad de San Marcos titulada "la difusíon del fútbol en Lima" sostiene que el fútbol en Perú fue introducido por inmigrantes británicos residentes en el Peru, marineros britânicos de paso en los puertos y jóvenes de la elite local que aprendieron el juego en Inglaterra y de regreso lo pratican en el Peru.

Poco a Poco, el deporte fue alcanzando otros espacios, como clubes deportivos formados por integrantes de la misma elite local y luego equipos de fútbol surgidos al interior de espacios educativos...

Una segunda manera em que el fútbol fue introducido en Lima fue a través de su práctica en centros laborales. Para la historiadora Alícia de Águila, la presencia del patrón al frente del equipo de fútbol fomentaba la fidelidad entre él y sus obreros. En un trabajo pionero de José Deustua, Steve Sein y Susan Stokes, se sostiene que un primer paso hacía el profesionalismo fué la creacíon de equipos de fútbol por las principales fábricas textiles de Lima y Vitarre. (2014, p. 47-48).

Paralelamente aos fatores da formação do futebol no país, é possível perceber em algumas obras peruanas sobre o tema, como o esporte também adquiriu grande popularidade no país, mesmo com os fracos resultados internacionais se transformando em uma paixão local.

Segundo o renomado escritor Mario Vargas Llosa (2011), prêmio nobel de literatura em 2010, em crônica intitulada "Una passíon llamada fútbol":

Acaso la explicacíon de este prodigioso fenómeno contemporáneo, la pasíon por el fútbol - un deporte elevado a la categoria de religión laica -, sea en realidad bastante menos complicada de lo que suponem los sociólogos y psicólogos que tratan de interpretalo y consista simplemente en que el fútbol ofrece a las gentes algo que apenas tienen: una ocasión de divertirse, de entretenerse, de entusismarse, de exaltarse, de vivir unas emociones intensas que la rutina cotidiana rara vez les depara. Querer entretenerse, divertirse, pasar un rato agardable, és la más legítima de las aspiraciones, un derecho tan válido como el querer comer y trabajar. Por razones múltiples y seguramente complejas el fútbol he venido a cumplir en el mundo de hoy esta funcíon con más éxito y universalidad que cualquier otro deporte. A quienes el fútbol nos gusta y nos da placer no nos sorpreende en absoluto la jerarquia que há alcanzado entre los entretenimentos colectivos, pero hay muchos que no lo entenden, y que además lo deploran y critican.

El fenómeno les parece lamentable porque, dicen, el fútbol enajena y empobrece intelectualmente la multitud, distrayéndola de los assuntos importantes. Quienes piensam así, olvidan que divertirse és un asunto importante. Olvidan tambíen que el característico de una diversíon, por intensa y absorbiente que sea y, un buen partido lo es en grado sumo, es ser efímera, intranscendente, inócua, una experiencia en la que el efecto desaparece al mismo tiempo que la causa. (2011, p. 30-31).

A forma poética como Llosa defende a paixão pelo futebol, elegendo o seu caráter universal de diversão como grande característica aglutinadora do esporte, enseja uma reflexão sobre a própria importância deste jogo nas formações identitárias latino-americanas e mesmo na existência efêmera dos indivíduos apaixonados pelo esporte.

A crítica que o literato faz àqueles que defendem a teoria do futebol como "ópio do povo" é simples, porém contundente. A intensidade de uma mera partida de futebol pode gerar experiências coletivas e sentimentos de pertencimento que, à margem das manipulações políticas ou econômicas, são fundamentais para a própria existência.

Outra importante referência literária encontrada nessa busca intelectual para compreender um pouco o que seria o imaginário coletivo peruano sobre o futebol, visto que, a produção acadêmica é escassa, é um ótimo romance policial escrito por um jovem talento chamado Santiago Roncagliolo, intitulado "La Pena Máxima”, no qual a própria divisão dos capítulos é 
feita pelas partidas disputadas pela seleção peruana e a final do torneio.

O autor constrói um enredo em que a história se passa durante o campeonato mundial realizado na Argentina e a participação da seleção peruana no torneio acaba sendo o pano de fundo de uma série de assassinatos e perseguições que envolvem inclusive agentes da Operação Condor.

O personagem principal, Félix Chacaltana, um funcionário público, arquivista, burocrata que não gostava de futebol, mas acaba indo inclusive à Argentina em uma investigação no centro de tortura da ESMA no dia em que os peruanos eram goleados pelos anfitriões, acaba sendo representado como uma exceção em meio à catarse coletiva que provocava a realização do torneio no Peru.

Trata-se de uma obra de ficção, mas que auxilia na percepção das representações existentes na memória coletiva sobre o país andino, principalmente no que diz respeito às possíveis mobilizações populares. Um exemplo está no trecho a seguir que se passa na estreia contra os escoceses:

Él queria librarse de ese paquete cuanto antes. Aquello no era algo que pudiese guardar en su casa hasta otra ocasión.

El problema era qué hacer mientras tanto. Se aburría. Con disimulo, se acercó a una ventana aberta, donde una família de trés niños estaba paralisada frente al televisor. Todos llevaban las casaquillas con la franja roja. Una de ellas ponía en letras negras a su espalda: CUBILLAS. Él se dejó mecer por la voz rítmica del narrador:

- Cubilla, se la passa a Velasquez. Marca férrea contra Velasquéz, que cae al suelo. El árbitro no pita nada y Velasquez se levanta. Sigue Velasquéz, haccia delante. Se la devuelve a Cubillas ya en el limite del área. Peligro, que Cueto se cuela entre dos defensas, recibe la pelota, encara al portero, la cambia ao palo izquierdo yyy...GOL! GOOOOOOOOOOOOOOOL peruano! Cueto número 8 haciendo magia con la perna izquierda y 1-1 em el marcador!

Las casas de Barrios Altos despertaron con un bramido ensurdecedor. Se oyeran muebles golpeando contra el suelo, aplausos, y sobre todo el grito de gol, una sola voz por todas partes, como si tronase en el cielo.

Agitada por el escándalo, la mochila roja se revolvío un poco y dejó escapar unos sollozos. De todos los paquetes del universo, hoy tenía que llevar precisamente ése. Un paquete sin nombre, sin instrucciones previas, sin control. (RONCAGLIOLO, 2014, p 12-13).

Diversas passagens ficcionais do romance remetem às narrações televisivas e radiofônicas dos gols, às intensas mobilizações populares nos dias das partidas, à idolatria em torno de jogadores como Cubillas, Cueto, Muñante, Chumpitaz etc, além das nebulosas especulações da derrota sofrida diante dos argentinos.

A Copa de 1978 era apenas o terceiro mundial em que os peruanos participaram da fase final. Além de estarem presentes na primeira edição realizada no Uruguai em 1930, obteve seu melhor desempenho no campeonato de setenta no México, quando dirigido pelo ex-craque Didi foi eliminado pela seleção brasileira nas quartas-de-final. Classificou-se também para o torneio da Espanha em 1982, última vez que o país conquistou uma vaga nas eliminatórias sul-americanas.

Este período pode ser considerado a melhor fase do futebol peruano no âmbito internacional devido ao bom futebol exibido pelas seleções, sobretudo, no torneio realizado no México em 1970 e na primeira fase do mundial da Argentina. Os peruanos também conquistaram pela segunda vez ${ }^{1}$ a Copa América de 1975, título mais importante da história do futebol do país.

Neste sentido, o presente artigo tem como objetivo analisar as representações coletivas geradas por veículos da imprensa brasileiros (Placar, Jornal do Brasil) e argentinos (Clarín, El Gráfico) sobre a campanha peruana no campeonato mundial de 1978.

\section{A) Seleção peruana como grata surpresa}

Antes de começar o torneio os peruanos estavam desacreditados. O grupo que estava seria difícil devido à presença da forte seleção holandesa, que era vice-campeã do mundo, e da Escócia, que também era considerada como uma favorita, além do Irã.

O plantel estaria dividido em dois grupos distintos numa rivalidade entre atletas do tradicional e popular clube do Alianza Lima e os jogadores do elitista Sporting Cristal. Efetivamente o grupo estava

\footnotetext{
${ }^{1}$ A primeira conquista foi em um torneio disputado em Lima em 1939 com a participação de apenas quatro seleções além da anfitriã (Uruguai, Paraguai, Chile, Equador), sendo que tanto o Brasil quanto a Argentina não disputaram a competição.
} 
"rachado" entre os jogadores dos dois times que formavam a base da equipe peruana. Um possível conflito racial é apontado por Pablo Llonto, ao afirmar que "para muchos jugadores de Cristal ellos eran los lindos y los de Alianza los negros feos". (LLONTO, 2005, p. 131).

O jornal Clárin registra o ambiente ruim antes da estreia da seleção peruana em reportagem intitulada "Los peruanos viven em tensíon":

El partido de sábado entre Escocia e Peru se vá transformando Córdoba en el centro de las expectativas. Mientras los escoceses siguen mostrando su potencia y su alegria, los peruanos respiran un clima de certa tensíon por el enfrentamiento de dos grupos antagónicos dentro del plantel (EL GRÁFICO, 01 jun. 1978, p. 22).

Entretanto, apesar das expectativas negativas, a seleção peruana acaba tendo um bom rendimento $\mathrm{e}$ derrota os escoceses que, segundo todos os veículos analisados, eram amplamente favoritos se transformando, assim, em grande surpresa na primeira rodada.

Em uma reportagem da revista Placar com a entrevista do técnico Marcos Calderón fica clara a condição da seleção peruana como a "zebra” do grupo, segundo o articulista da matéria:

Escalado na chave de Holanda e Escócia, o Peru não tem condições de surpreender ninguém, nem mesmo os seus torcedores, que se conforma com a simples presença da seleção na Copa. Só o técnico sonha com algo mais.

\section{Declarações do técnico: Marcos Calderón:}

Nosso futebol é igual ao brasileiro. Buscamos sempre o gol, como vocês. Contra times fortes, preferimos usar os contra-ataques. Tomamos cuidado para não abrir espaços na defesa e cuidamos de bloquear todos os setores, a partir do meio de campo...

Os goleiros são Ramon Quiroga e Otorino Sartori. E se for preciso um terceiro, Juan Papelito Cáceres. Quiroga é um argentino naturalizado as pressas para que pudesse disputar as eliminatórias: tem 26 anos, 1,76 e é o melhor dos três. Desde que Rubiños falhou no México diminuindo as chances do time, a ideia de que o Peru não produz bons goleiros tomou conta de todos. (PLACAR, n.420, p. 44-45).

Além da afirmação sobre a seleção peruana não ter a menor chance e os torcedores, inclusive, não alimentarem nenhuma expectativa, o próprio técnico é tratado de forma irônica, como um "sonhador", por causa das próprias declarações.

A comparação com o futebol brasileiro e a segurança na disposição tática do time segundo o técnico foram interpretadas como uma ilusão, quiçá, um ultraje.

É importante destacar também a justificativa apresentada para a escolha do argentino naturalizado Quiroga, importante figura na estreia peruana. Além de a princípio se basear em um critério exclusivamente técnico, "o melhor dos três", remete ao senso comum e ao próprio arqueiro da seleção de 1970.

A revista $E l$ Gráfico, ressalta na manchete sobre a partida: "En teoria una derota de Escocia parecía imposible. Pero en campo la realidad fue absolutamente otra. La solvencia de Quiroga, el talento de Cubillas, la inteligência de Cueto, la frialdad de un equipo. Por eso, lo de Peru no fue um milagro" (p. 32). $\mathrm{O}$ ex-jogador e cronista Silvio Marzolino ${ }^{2}$ confessou seu espanto:

Debo ser sincero: fui al estadio de Córdoba totalmente convencido de que Escocia le ganaria a Perú. Por qué? Por el trabajo prévio de Perú - lo vi mal en sus dos partidos contra Argentina - por el clima de intranquilidad íntima que se vívia en su concentracíon - se hablaba incluso de peleas entre ellos $-\mathrm{y}$ porque además de estos factores, su defensa me resultaba débil para contener un trío ofensivo como el escocês. Dicho más claramente: la experiencia de Chumpitaz era muy poca para cobrir tantas deficiências...

Y dejo para lo último el mejor jugador del campo: Teófilo Cubillas. Hizo todo. Desde generar fútbol hasta concretarlo en gol. Podría escribir muchas líneas sobre él y su actuacíon. Pero creo que hay una frase que lo define mejor: volvío a ser el Cubillas del 70 , un jugador de toda la cancha que hasta ahora cumplió la mejor actuacíon que he visto en el Mundial. (EL GRÁFICO, n. 3061, 06 jun. 1978, p 35).

É interessante constatar a estupefação do articulista que, primeiramente, busca explicar as razões pelas quais acreditava que a Escócia era a grande favorita para vencer a partida: as más atuações

\footnotetext{
${ }^{2}$ Nascido em 1940, Sílvio Marzolino iniciou sua carreira no Ferrocaril Oeste, destacando-se como jogador do Boca Juniors, por onde atuou por 12 anos. Integrou diversas vezes a seleção argentina e disputou a Copa da Inglaterra em 1966, quando foi eleito o melhor lateral-esquerdo do torneio. Trabalhou também como técnico e cronista esportivo.
} 
da seleção peruana em amistosos contra a Argentina antes da Copa, o ambiente ruim dentro do grupo de jogadores, além de uma suposta fragilidade defensiva da equipe diante de outra seleção considerada forte e muito ofensiva.

No segundo trecho destacado é possível perceber uma reverência ao jogador Cubillas, cérebro da equipe, e um dos remanescentes da seleção peruana de setenta. Símbolo maior do período de ouro do futebol peruano, que segundo outra reportagem da mesma edição da revista, além de ter feito a melhor atuação individual da primeira rodada, seria um dos grandes jogadores do mundo:

Teófilo Cubillas és su nombre. 29 años. Del Alianza Lima. Y lleva en su espalda el número que desde siempre ha venido identificado a los grandes: el 10. Entero, flerte, sereno, imaginativo, desenvolvío la vieja pero no gastada batuta de aquel Perú de 1970 y dijo que se podía, que no hay nada de imposible. Y el hamanaque, la finta, la pisada, el toque, la viveza para estar paradito allí donde no hay nadie, la firmeza para aguantar un choque. Todo, hasta el remate maravilloso del segundo gol. Hasta el derechazo impecable, sorpreendente, poco menos increíble del tiro libre que se convertío en el terceiro.

Bajo su influjo, sobre su fútbol, entre las cuatro o más paredes con que nos regaló todo un estádio dijo "Contigo Perú".

Es peruano, es latinoamericano. Pero es del mundo porque juega al fútbol. Teófilo Cubillas es su nombre. (EL GRÁFICO, n.3061, 06 jun. 1978, p. 35).

O jogador peruano é representado como um craque habilidoso, clássico armador que dribla, toca, cadencia o jogo e marca gols importantes. Cubillas, na realidade, acabou sendo o vice-artilheiro do mundial com cinco gols, ao lado do holandês Resembrink.

A seleção peruana de setenta paradoxalmente se transforma em referência no país andino, e Cubillas acaba representando uma espécie de acionador da memória técnica da equipe dirigida pelo brasileiro Didi na copa do México. Inclusive, Cubillas, em entrevista para El Gráfico, enaltece o meia brasileiro como principal técnico na sua carreira:

Didi fue el técnico que más cosas me ensenõ. Yo siempre jugué de 10 adelantado. Didi me convenció que debía tirarme atrás para arrancar con mas panorama y la pelota dominada. De esa manera podia encarar con mayor seguridad. O sea que mi manera de plantarme en la cancha se la debo a él. Y además me enseño a pegarle la pelota. Me quedaba después de los entrenamientos ejecutando tiros libres y el me acompañaba para perfeccionarme. (EL GRÁFICO, n. 3062, 13 jun. 1978, p. 50).

A reverência ao ex-técnico Didi e capitão do primeiro título conquistado pelo Brasil aproxima ainda mais o talento de Cubillas e a equipe que estava disputando o mundial da Argentina com a seleção peruana de setenta. E metaforicamente, com a própria imagem positiva do futebol brasileiro.

Em reportagem do Jornal do Brasil, além do meia armador, outro remanescente de setenta, o zagueiro Chumpitaz, comenta o triunfo sobre os escoceses:

Na opinião de Cubillas, a classificação para a segunda fase está quase garantida principalmente se o Peru conseguir um empate diante da Holanda. A exemplo de Calderón disse que a sua equipe estava muito nervosa no início da partida e por isso tomou o primeiro gol. Para ele, o goleiro Quiroga foi o principal responsável pela vitória sobre a Escócia ao defender um pênalti quando o resultado era 1 a 1 . Chumpitaz, outro veterano da Seleção considera essa equipe individualmente inferior a de 1970, quando dirigida por Didi, passou pela fase de classificação e só se desclassificou ao ser derrotado pelo Brasil. Entretanto, a atual possui maior conjunto e adota um esquema de jogo mais competitivo. (JORNAL DO BRASIL, CADERNO DE ESPORTES, 05 jun. 1978, p. 5).

É possível perceber que os dois experientes jogadores buscam passar confiança para a continuação do torneio e que a seleção de setenta no Peru era efetivamente a grande referência da equipe, conforme assinala Chumpitaz.

A vitória peruana, segundo reportagem do jornal Clarín, teria influenciado inclusive o ambiente político do país com a suspensão temporária no toque de recolher, isso devido a uma grande comoção popular:

Peru retorna hoy a la realidad que convoca hoy el toque de queda, después que el triunfo de su representativo que interviene en el Campeonato Mundial de la Argentina le diera a su pueblo un inesperado y brillante triunfo sobre a Escocia. Las atajadas del golero Quiroga, las genialidades de Cubillas y hasta los gritos del director técnico Calderón, visiones todas que quedarán fotografiados en los mejores recuerdos deste pueblo, traídos por la 
televisíon desde Córdoba han dado un gran respiro en el clima de pressiones sócio-económicas actuales.

La pitada final del partido jugado el sábado dio lugar, a partir de ese momento a una fiesta espontánea que ganó las calles de Lima y presumidamente de todo el país, motivo por lo cual el gobierno resolvió levantar el toque de queda.

La medida volverá a reagir a partir de esta medianoche y hasta las cuatro del lunes. (CLARÍN, n. $11.588,05$ jun. 1978 , p. 18).

O registro das mobilizações populares em Lima e possivelmente em todo o país que teriam ensejado a suspensão do toque de recolher revela a força simbólica que o futebol efetivamente possui em determinadas situações políticas.

A caracterização da vitória como brilhante e inesperada demonstra que na realidade a seleção peruana durante o início do torneio era considerada fraca e muito inferior aos adversários europeus, porém se transformou em grande surpresa.

A ditadura de Francisco Bermudez Moralez estava em processo de deterioração devido a grave crise econômica e a pressão social por mudanças políticas. O ditador já havia convocado eleições parlamentares no país, que aconteceriam durante o Mundial.

Uma nota no Jornal do Brasil registra a pressão de movimentos de esquerda no Peru que teriam se colocado publicamente contra a ditadura argentina e a organização do mundial:

Organizações sindicais e políticas do Peru "repudiaram" a campanha montada pela ditadura militar na Argentina" para utilizar o campeonato mundial em benefício próprio. Afirmaram que o governo argentino "se apoia na repressão brutal" e que com a organização da Copa no melhor "estilo Alemanha nazista", pretende demonstrar que na Argentina os direitos humanos são respeitados. Reafirmaram também a "solidariedade com a resistência que o povo argentino opõem a ditadura" e responsabilizaram o governo argentino pela segurança dos peruanos que foram assistir a Copa. Este documento foi emitido pela facção da Confederação Nacional dos trabalhadores, pelo Movimento Sindical Cristão e pela Confederação Nacional Agrária e subscrita por várias Federações de esquerda e extrema esquerda, assim como pelos Partida Socialista Revolucionário, Unidade Democrática Popular e Comunista Revolucionário. (JORNAL DO BRASIL, 04 jun. 1978, p. 34).
A nota é interessante na medida em que possibilita constatar como a divulgação de eventuais críticas ao mundial e à organização da ditadura só aparecem eventualmente nas páginas do periódico brasileiro.

$\mathrm{O}$ fato de grupos de esquerda peruanos se posicionarem publicamente contra a realização do evento organizado pela ditadura argentina denota uma pressão sobre os regimes autoritários latino-americanos e sobre o próprio ditador Francisco Moralez Bermudez no país, mas isso não impediu que muitos peruanos tenham se mobilizado inclusive para irem torcer pela seleção na Argentina:

Muitos torcedores peruanos foram ontem ao aeroporto de Plumerillos para recepcionar sua seleção, que desembarcou nesta cidade as 15 horas, guardada por forte esquema de segurança. Impedidos de falar com os jogadores, o grupo acompanhou a delegação até o Hotel San Francisco, num corso formado por 80 automóveis.

As ruas de Mendoza só agora passaram a viver realmente o clima da Copa do Mundo, pois com a chegada da delegação do Peru muitos torcedores já se encontram aqui para assistir a partida de quarta-feira contra a Holanda e por onde passam fazem sempre muito barulho. Outros quatro mil devem chegar ainda hoje. (JORNAL DO BRASIL, CADERNO DE ESPORTES, 05 jun. 1978, p. 4).

O apoio da torcida registrado após a vitória sobre os escoceses acabou se transformando em euforia quando os peruanos conseguiram um empate com a forte Holanda e venceram o Irã, conquistando uma vaga entre as oito seleções classificadas para a segunda fase, no mesmo grupo de Argentina, Brasil e Polônia.

\section{B) A transformação do "inesperado" Peru refinado em polêmico vilão}

A primeira partida da "surpreendente" equipe peruana na segunda fase acabou sendo justamente contra os brasileiros, que tiveram muitas dificuldades para se classificar na primeira fase do torneio. A expectativa em torno do confronto gerou representações que aproximavam o futebol peruano do brasileiro. Uma reportagem do Clarín, por exemplo, foi intitulada "Brasil x Perú: duelo de un mesmo estilo":

Será el choque de dos invictos y también de dos equipos que le ponem color sudamericano a este grupo B de la segunda vuelta final. Perú x Brasil 
a partir de las $16: 45$ y comenzarán a escribir la segunda parte de su historia en este Mundial.

Volvemos ao principio. Ninguno de los dos conocieran la derota, pero la clasificacíon de cada uno tuve dimensiones diferentes y un sabor distinto. Perú se entremezcló con la hazãna, Brasil tiene una idea aproximada de milagro.

No hay ninguna duda que los cinco puntos de Perú en el grupo IV fueron una de las grandes sorpresas del torneo. Ahí concluyó su actuacíon liderando holgadamente, diríamos sin sobressaltos, logró un contundente marcador frente a Escócia, empató con Holanda y ganó com Irán.

La mayor virtude del Perú fué aferrarse a su tradicional estilo y adecuarlo a los hombres que en ese momento integran su formacíon. Del respeto inicial a sus rivales grandes, pasó, en último partido, a creer totalmente en su fuerza como equipo.

Todo su andamiaje se sustenta en una línea de cuatro bien ordenada y se respalda en el medio campo donde sobresale el talento del moreno Teófilo Cubillas, quien se transformó en el conductor de la equipo.

Lo de Brasil es distinto, porque recíen en el partido de domingo pasado pudo conseguir su clasificacíon. Debío sufrir más de la cuenta para estar presente en parte del torneo. (CLARÍN, SUPLEMENTO MUNDIAL, n. 11.597, 14 jun. 1978, p. 12).

É possível perceber o reforço argumentativo em reportagens anteriores. Enquanto o Peru foi uma das sensações da primeira fase, provavelmente a maior surpresa que teria conquistado uma façanha, o Brasil teria decepcionado e frustrado as expectativas em torno do mítico "jogo bonito".

A representação da equipe andina, além de positiva, é atrelada a ideia de um suposto estilo tradicional peruano que efetivamente não é explicado e estaria associado naquele momento com as supostas virtudes técnicas que englobariam "o futebol sul-americano", em oposição ao modelo europeu.

Sempre que aparece uma equipe oriunda de um país do continente e de qualidade futebolística, a tendência dos veículos midiáticos é compará-las com as grandes seleções dos países mais tradicionais, associando o bom futebol praticado com hipotéticas e genéricas características inatas "sul-americanas".

A boa equipe peruana comandada pelo reverenciado "moreno" Cubillas foi alçada ao mesmo patamar do idealizado futebol brasileiro, que até então, concretamente, havia apresentado um desempenho técnico pífio na competição.

A comparação com o futebol brasileiro é reforçada por Pelé ${ }^{3}$ por meio de sua condição como autoridade no assunto:

Lo cual és una carta de resultados impressionante, para un equipo nacional que yo entiendo estaba debajo del nível estabelecido por aquel otro sorpreendente equipo peruano que llegó a los cuartos de final bajo las órdenes de mi viejo mentor brasileño Didi y suelo fueron eliminados por Brasil en el campeonato de México en 1970. En aquella ocasíon tuvieron el infortúnio de encontrar con un equipo en su mejor momento.

El progreso de Perú és especialmente significativo desde el momento que ellos són, segun las interpretaciones de su performance en Buenos Aires más parecidos al viejo Brasil - el Brasil en el que jugué - que los próprios jugadores brasileños del selecionado actual. Mucho menos europeos en su estilo, que el equipo de transicíon brasileño de Claudio Coutinho. Menos europeos que México, que poco há se beneficiado de la transformacíon de su tácticas. Menos europeos que la Argentina, que há modificado su juego y está tratando ahora de demonstrar su capacidad a uma mayor velocidad. De hecho los peruanos constituyen el único conjunto con uma técnica auténticamente latinoamericana del torneo, lo que puede ser interpretado tanto como una condena de los demás por cambiar a una forma no natural de fútbol, o un elogio a su director técnico por insistir que Perú, por lo menos que quede como és...

Como todos los latinos solían hacer en una época, a los peruanos les gusta retener la pelota, jugar con ella. Prefieren al juego de passe corto, pero también pueden jugar a pelotas largas. Yo puedo apreciar especialmente la forma en que Peru lleva a cabo las veloces paredes que tanto disfrutaba yo con Coutinho (no se trata del técnico actual) en el Santos y con el Tostão para Brasil. Elos tambíen saben passar cambiar el ritmo, passando del juego lento a un sorpresivo passe en velocidad. (CLARÍN, SUPLEMENTO MUNDIAL, n. 11.597, 14 jun. 1978, p. 8-9).

\footnotetext{
${ }^{3}$ É importante destacar que o ex-jogador Édson Arantes do Nascimento, mundialmente conhecido como Pelé, assinava uma coluna que era publicada quase diariamente no suplemento mundial do Clarín e na minha opinião foi uma das figuras legitimadoras da realização do evento organizado pela sangrenta ditadura argentina comandada pelo general Jorge Rafael Videla conhecida como Processo.
} 
As interessantes afirmações escritas, traduzidas, narradas ou até mesmo atribuídas ao cronista Édson possibilitam boas reflexões sobre a construção dos estereotipados estilos de jogo. Após destacar na primeira parte da citação que também foi surpreendido com a campanha do selecionado peruano. Para introduzir o tema, o ex-atleta aciona a memória da boa equipe do país em setenta, que era dirigida pelo reverenciado Didi.

No segundo parágrafo da citação é possível perceber a construção do futebol peruano como representante, naquele momento, do mais "autêntico" latino-americano e que se assemelhava ao "velho Brasil". Seria muito menos "europeu" que a própria seleção dirigida por Coutinho, o México ou até mesmo a Argentina de Menotti, segundo o texto, e tinha permanecido como aquilo que o Peru é!

A retumbante resposta está no último trecho selecionado da crônica. "Como todos os latinos", os peruanos prendem a bola, efetuam passes curtos, fazem boas tabelas, cadenciam a partida, apesar de saberem utilizar a velocidade também. Ou seja, jogam de forma artística, tem "viveza", seriam "fenomenais", segundo o cronista, que foi considerado o maior jogador do século XX.

Na segunda fase o "estiloso" futebol peruano decepciona, sendo derrotado pelo Brasil por 3x0 e pela Polônia por $1 \times 0$. Foi eliminado da competição na mesma data em que eram realizadas eleições legislativas no país, que não ocorriam desde 1968 :

A grande maioria dos eleitores peruanos acorreu as urnas na parte da manhã, a fim de poder assistir depois ao jogo da sua seleção com a Polônia, iniciado as 11:45 e que duas horas mais tarde provocava nova decepção com a derrota que transformou em fumaça todos os sonhos criados pelas boas exibições da equipe na fase inicial da Copa do Mundo (JORNAL DO BRASIL, n. 72, 19 jun. 1978, p. 9).

Apesar da decepção futebolística em importante data cívica, ainda faltava uma partida a ser cumprida pela seleção peruana, fundamental na definição de qual seria o vencedor do grupo e, consequentemente, disputaria a final do mundial. Confronto que suscita polêmicas e acusações no Brasil e na própria Argentina com um processo de enquadramento de memória sobre o mundial realizado no país. ${ }^{4}$

\footnotetext{
${ }^{4}$ Sobre o tema, escrevi um artigo: "Argentina 6 x 0 Peru -A partida mais longa
}

Diversas são as especulações sobre a partida e surgidas, sobretudo, a posteriori. Suborno dos jogadores peruanos e/ou do técnico; acordo entre os ditadores Jorge Rafael Videla e Francisco Bermudez Moralez sobre a troca de prisioneiros considerados "subversivos"; fornecimento de diversas toneladas de trigo pelo governo argentino ao peruano; facilitação do arqueiro Quiroga, devido ao seu vínculo de nascimento com a Argentina. Foge ao escopo deste artigo comprovar qualquer uma das hipóteses aventadas nas décadas posteriores. Primeiro, pelo fato de o presente trabalho focar na análise de representações que ocorreram no momento da realização do mundial; e, segundo, pela própria dificuldade para obter fontes confiáveis ou relatos fidedignos, apesar de todas as plausíveis suspeitas.

A escalação de Quiroga, por exemplo, é um tema polêmico e aparece nas reportagens anteriores a partida. $\mathrm{O}$ fato de o goleiro Ramón Quiroga ser um argentino da cidade de Rosário e naturalizado peruano desencadeou muitas suspeitas sobre a sua atuação e uma possível contribuição com o país de origem.

$\mathrm{O}$ arqueiro, cujo apelido era "Chupete", jogava no Sporting Cristal e era reconhecido no Peru e na Argentina por sua capacidade técnica e espírito de liderança. A sua escalação na partida teria sido contestada por alguns jornalistas. Segundo o autor Pablo Llonto, mesmo entre os jogadores, visto que o Peru já estava eliminado, a situação do atleta era no mínimo incômoda:

"Chupete" Quiroga el arquero argentino nacionalizado peruano, fue puesto en observacíon por el plantel. Nadie se animo a decirle en la cara que no debía jugar para evitar sospechas, pero un jugador le hizo la pregunta inevitable:

- Chupete, estás seguro que se siente bien para jugar? le dijo Muñante.

Oye Huévon - contestó Quiroga en el linguaje de su nueva tierra. Tu crées que yo vine aqui para que chucha? Vine a jugar el mundial y lo juego". (2005, p. 142).

O jogador teria sido entrevistado antes da partida sobre o atípico fato em reportagem do jornal Clarín intitulada "Quiroga, una situacíon muy difícil", na

da história das Copas do Mundo por dois jornalistas memorialistas argentinos", no qual é analisada a abordagem da partida tomando como referência Pablo Llonto e Ricardo Gotta. 
qual responde, entre outras coisas, sobre a possibilidade de enfrentar a Argentina e quem seria o campeão do torneio:

- Es cierto que pediste no enfrentar los argentinos?

- Si y no.

- Como és eso.

- Yo profesionalmente no tengo inconvenientes para jugar. Lo haría tranquilamente y sin complejos. Me conosco demasiado bien y sé que en el medio de la partida me comportaria como si los hombres de Menotti fuesen japoneses, franceses o chinos. De toda manera hablé con el técnico Calderón. Simplemente le dije que sí creia conveniente sacarme de le equipo, lo hiciera sin ningún problema. Eso va a servir para evitar cualquier tipo de suspechas. Más por él y todo el resto de los muchachos. Pero quiero advertilo bien. Si me ponem, juego. Y si juego, soy capaz de dejar la vida bajo los trés palos peruanos.

- Quien sale campeón?

Para mí, Argentina. Pero mejor no lo pongas. Todavia tiene que ganar a nosotros y la gente podría pensar mal de mí... (CLARÍN, SUPLEMENTO MUNDIAL, n. 11.604, 21 jun. 1978, p. 7).

É possível perceber que a escalação suscitava questionamentos e possivelmente o mais sensato teria sido não escalar o goleiro naturalizado, independente de ter ou não melhores condições técnicas que os outros. O receio na afirmação de que a Argentina seria a campeã denota também o clima em torno do jogador.

E, de acordo com o periódico, a responsabilidade acabou sendo totalmente do técnico, como é possível perceber pela nota "Es Peruano", posicionada logo abaixo da entrevista do goleiro:

Rosario es um mar de de rumores. Es difícil llegar a escuchar todos. Y ocupan distintos rubros. El único que podemos, por lo menos recoger testimonios es el de la nacionalidad del arquero Quiroga. Nacido en Rosário y hoy titular de la seleccíon peruana. Para tener la palabra oficial entrevistamos ao señor Calderón. El técnico fue parco y contundente. "Para mí Quiroga és un peruano más”. Así que sí está bien fisicamente va a jugar como si fuera cualquier partido. (CLARÍN, SUPLEMENTO MUNDIAL, $\mathrm{n}$. 11.604, 21 jun. 1978, p. 7).

Um dos rumores apontados no periódico seria o suposto oferecimento de "mala branca" de ambas as partes a partir de jornalistas peruanos. Em nota intitulada "Incentivacíon", afirmam que:
El referido despacho, fechado en la víspera da cuenta que la Confederacíon Brasileña de Deportes "há enviado há Rosário dos enviados con los bolsillos llenos de dólares para estimular los jugadores peruanos". Según la agencia oficial de notícias, la informacíon la habían suministrados los enviados especiales de los diários limeños "Ojo" y "Sorreo". Los citados periodistas dejan constância - según Télam - de que la incentivacíon a la cual es ajena la Federacíon Peruana alcanzaría la soma de 6000 dólares para cada jugador peruano en el caso de conseguir vencer los argentinos.

La espécie tiene su contrapartida. El cable tambíen destaca que la Argentina se mostro interesada en premiar el empeño de los polacos, adversários de Brasil según fuentes brasileñas. (CLARÍN, SUPLEMENTO MUNDIAL, n. 11.604, 21 jun. 1978, p. 5).

A suposta "mala branca" brasileira também é mencionada na revista Placar:

Aí já se falava em dinheiro, em compra e venda de jogo, os argentinos estavam apavorados com as notícias de que o Brasil estava oferecendo conforto e vida boa aos jogadores peruanos, para vencerem a partida. Os repórteres dos jornais de Buenos Aires ficaram sabendo que dois cartolas brasileiros - Mozart Di Giorgio e Armando Marques - foram a Córdoba fazer uma oferta aos peruanos antes de sua viagem para Rosário. Uma emissora de televisão chegou a fazer raiva nos argentinos quando chegou a anunciar em edição extra, que a prefeitura de Recife oferecera um lote na praia para cada jogador peruano. Nada porém foi confirmado nem nunca será. (PLACAR, n. 427, 30 jun. 1978, p. 41).

As notícias relatadas servem apenas para mostrar que as polêmicas sobre a partida já existiam antes mesmo do início do jogo. "Malas brancas", a situação da naturalização de Quiroga e a própria questão dos horários distintos de ambos os confrontos decisivos 5 , revelam um ambiente tenso e sujeito a especulações.

Com relação à efetiva atuação da equipe peruana, o periódico afirmou que "Perú cumplío hasta que pudo" e Quiroga não podia ser culpado pelos seis gols:

\footnotetext{
${ }^{5}$ As partidas decisivas Brasil 3x1 Polônia e Argentina 6 x0 Peru foram disputadas em horários distintos, sendo que os anfitriões tinham conhecimento do resultado que necessitavam pois jogaram depois da seleção brasileira. Cabe ressaltar que este fato já estava estabelecido previamente no regulamento do torneio e que a Argentina sempre jogava no horário posterior em função das transmissões televisivas.
} 
La seleccíon peruana tenía tambíen un papel difícil. Con el resultado "puesto" de Brasil-Polônia debía erigirse en juez de la Argentina. Jugar contra la desesperacíon de nuestra equipe y hacerlo frente a los ojos del mundo entero. Cumplió su missíon hasta donde pudo. Quiso frenar el vértigo argentino y sorpreender con el contraataque. Casi logra via Muñante, que reventó un pelotazo en el palo derecho del arco de Fillol, ou via Oblitas, que le ganó las espaldas a Olguín a los 15 minutos del primer tempo. Pero después sucumbío a la pressíon, de adentro y de afuera. Y no pudo evitar la goleada, consagratoria para el rival.

Quiroga: Sobrellevó el peso psicológico previo al partido. Su condicíon de Rosarino lo puso en el centro de la espera. Pero no tuvo culpa de nada. En todos los goles se encontró muy desamparado frente a rivales que llegaron con la pelota a su favor. (CLARÍN, SUPLEMENTO MUNDIAL, n. 11.605, 22 jun. 1978, p. 6).

É possível identificar primeiramente o argumento de que a equipe peruana, apesar de eliminada, estaria pressionada pelas circunstâncias que envolviam a partida tanto dentro, quanto fora dos gramados. Seria o "fiel da balança" e o mundo inteiro estaria atento ao seu desempenho e de seus jogadores.

Neste sentido, o goleiro Quiroga é isento de qualquer responsabilidade sobre os seis gols e teria superado o aspecto psicológico de ter de enfentrar sua pátria "mãe".

A referência à execução de duas jogadas perigosas no início da partida, sobretudo o chute na trave do ponteiro Muñante, ensejam uma credibilidade na determinação da equipe peruana em dificultar a "missão" argentina.

É interessante observar que o atacante Muñante por jogar no México e ter um ótimo salário não é mencionado como suspeito de suborno por nenhum jornalista ou companheiro nas diversas denúncias posteriores. $\mathrm{O}$ fato de quase ter marcado um gol no início do jogo, desferindo potente chute na trave, ajuda a proteger sua imagem e, segundo autores como Llonto, foi utilizada também durante muito tempo como prova de idoneidade da própria seleção peruana:

Como en las películas de Hollywood, antes del final previsible y feliz, se pudo ver um poco de suspenso para desalentar los mal pensados: a los dos minutos del primer tiempo, Muñante estrelló un tiro en el poste. Esa jugada fué con el tiempo- la carta más valiosa que usaron todos los jugadores peruanos para demonstrar que el resultado del partido no estaba arreglado.( 2005, p. 150-151).

Em reportagem da revista El Gráfico os principais argumentos que defenderiam a moral da equipe peruana são distintos:

No podemos aseverar que estemos seis goles arriba de Perú, aunque en nuestras últimas confrontaciones los hemos superado ampliamente, siendo locales y visitantes. No sabemos sí, estando Peru en posicíon más expectante, com algún resto de ilusíon, con algo de chance, podíamos haberlos goleado con tanta amplitud y contundencia. Nadie podrá saberlo. Y a esta altura de los acontecimientos, importa muy poco. És indudable que Perú nos resultó más fácil que a Brasil, cuando lo venció 3 a 0 o a Holanda, cuando sólo conseguío empatarle. En esos encuentros, Perú estaba más entero, con más ilusíon, más fibra combativa. Pero en cambio, necessitamos trabajar más y jugar mejor que Brasil y Holanda para golear a los peruanos. Ningun gol nos vino de regalo, como pudo serlo el segundo de Brasil, falla de Quiroga que se produjo en el momento psicologicamente justo, para cortar una clara reaccíon peruana. No metimos ningun tiro libre. Todos fueron jugadas elaboradas (EL GRÁFICO, EDIÇÃO EXTRA, 23 jun. 1978, p. 19).

O primeiro trecho destacado enfatiza o suposto estado anímico dos jogadores peruanos em uma partida na qual já estavam eliminados. Afirma que os argentinos eram superiores, mas que não seria possível afirmar que o placar poderia ser tão dilatado se eles estivessem em uma situação mais favorável, inteiro, com aspirações na competição como quando enfrentaram o Brasil ou até mesmo a Holanda na primeira fase do torneio.

O segundo argumento, que aparenta ser uma provocação aos brasileiros, é de que todos os gols foram jogadas elaboradas, construídas pela equipe argentina, enquanto na vitória da equipe de Coutinho sobre os peruanos, Quiroga teria falhado e os gols teriam saído de bola parada.

Nos veículos brasileiros analisados existe uma mescla de indignação com a atuação do Peru e resignação diante da falta de capacidade da equipe brasileira ter se imposto como uma seleção ofensiva. $\mathrm{Na}$ revista Placar, na reportagem, “O Peru exagerou!", 
são feitas diversas acusações veementes pelo jornalista Sérgio Carvalho ${ }^{6}$ :

O Peru perdeu para a Argentina por 6 a 0 , sem resistância alguma, entregando com muita naturalidade uma vitória que classificou a dona da festa para a grande esperada final.

Em nenhum momento daquele jogo o Peru, simulou estar disputando uma partida de Copa. Estava aí como uma presa, esperando ser arrasada pelo inimigo. Nem mesmo quando Muñante conseguiu vencer Fillol e acertar a trave direita, ou quando Oblitas - cara a cara com Fillol - chutou longe do gol, o Peru demonstrou seriedade na sua atuação...

Ninguém podia fazer nada. De nervosos e inseguros no início os argentinos estavam absolutamente calmos e conscientes já na metade do jogo. O Peru ajudando. E como ajudou. Quesada queria tirar de calcanhar as bolas que caíam na área. Velasquez queria driblar todo o ataque argentino dentro de sua própria área. Enfim os peruanos simularam um esforço que parecia até coisa de cinema.

O único a lutar e decidir com raça as jogadas que disputou, a aparentar vontade de vencer foi o veterano Chumpitaz - disputando sua última partida oficial pelo Peru. A Quiroga não se pode culpar pelo bombardeio que seu gol sofreu. Durante três dias ele transformou-se na figura mais importante da decisão: um argentino naturalizado peruano, acusado de ter se vendido num jogo em Rosário pelo campeonato local, o que provocou sua saída forçada do país...

Eu não pude entender bem tudo aquilo. Já vi times tremerem diante da força de um adversário superior, mas não se entregarem. $\mathrm{O}$ time argentino é cheio de defeitos e poucos são os jogadores de categoria. Não tem a força que aqueles 6 a 0 insinuaram mas o Peru não revelou, no resultado, a grandeza de sua honra esportiva tão exaltada por Calderón. Não havia explicação para isto, e mesmo assim queria ouvir alguém do Peru dizer o que aconteceu, numa versão oficial. O técnico e o capitão Chumpitaz não comapreceram a entrevista coletiva oficial depois

\footnotetext{
${ }^{6}$ Sérgio Carvalho nasceu em São José do Rio Preto, interior do Estado de São Paulo. Começou a carreira na Rádio Difusora de Monte Aprazível como apresentador de programa esportivo. Em São Paulo trabalhou na TV Record (como produtor e apresentador de programa esportivo) e na Rádio Bandeirantes (como repórter de campo). Esteve ainda nos jornais paulistanos A Gazeta, Folha da Tarde, Notícias Populares, Popular da Tarde (onde foi diretor de redação) e Diário Popular. Cobriu seis Copas do Mundo de Futebol, sendo primeira a da Argentina e como correspondente da revista Placar. Foi presidente da ACEESP e da ABRACE (Associação Brasileira de Cronistas Esportivos). Hoje escreve a coluna "Toque de Bola" para o site Futebol Interior e é presidente da ACEISP (Associação dos Cronistas do Interior de São Paulo).
}

de todos os jogos. (PLACAR, n. 427, 30 jun. 1978, p. 40-42).

De todo material pesquisado na elaboração da minha tese sobre o mundial de 1978, essa matéria é, sem dúvida, a mais contundente no sentido de denunciar a passividade da seleção peruana na partida. A indignação com a atuação da equipe comandada por Calderón é flagrante, bem como as acusações veladas e explícitas de que o time teria entregue o jogo.

Curiosamente, além do zagueiro veterano Chumpitaz que teria jogado com extrema vontade e estaria se despedindo da seleção peruana, o repórter somente isenta o goleiro Quiroga da responsabilidade pela derrota, mesmo ressalvando que ele teria sido acusado anteriormente de suborno em seu país.

A revolta se acentua com insinuações à falta de "honra desportiva" da equipe e a ausência de qualquer representante da delegação peruana após a partida.

A representação da vilania do Peru, conforme relatada na referida reportagem da revista, contrastava com declarações de resignação e acusações à ineficiência da seleção brasileira em diversas outras reportagens e na seção de cartas da revista, por exemplo, dois depoimentos refletem bem essa outra visão que de certa forma absolve a culpa peruana:

Com o Peru o Brasil morreu de véspera mas eu acho que o Brasil morreu de antevéspera ao empatar com os argentinos que estavam morrendo de medo da camisa canarinho. Então pergunto, será que não há nenhum cara suficientemente honesto na comissão técnica para confessar que o Peru pagou o pato?

ISHIRO NAKAHASHI. MARINGÁ - PR.

Vejam só que o Peru levou três gols do Brasil e seis da Argentina. Isto é, levou goleada dos dois times sul-americanos. Então, não compreendo por que se acusa os peruanos de facilitar a vitória argentina. Se o contrário acontecesse, isso é se o Brasil estivesse no lugar da Argentina, nós iríamos aceitar o argumento com a mesma convicção.

ANA MARIA VICENNATTI. SANTOS - SP.

É importante esclarecer que, apesar de serem cartas de leitores e não textos de emissores diretos, foram selecionadas pela revista, constituindo-se assim como fontes interessantes e factíveis.

Isso posto, a teoria de que o Peru estava sendo acusado injustamente de entregar a partida e a goleada argentina era plausível, é um discurso recorrente 
também em fontes brasileiras, apesar das suspeitas e eventuais revoltas.

O escritor e humorista Carlos Eduardo Novaes ${ }^{7}$ ironiza a culpabilidade do país na jocosa crônica "O Peru expiatório (na falta do bode)", cujos trechos serão aqui reproduzidos. Apesar de caricata, é emblemática no quesito ambiguidade das representações surgidas nos veículos brasileiros analisados:

Bem meus caros, chegamos ao final de mais uma Copa do Mundo. Recolhemos as bandeiras, varremos o papel picado, depositamos as emoções na poupança e nos instalamos britanicamente diante da televisão a espera do jogo decisivo entre a melhor técnica (Holanda) maior garra (Argentina), torcendo provavelmente para os louros holandeses já que nosso sentimento de latinidade foi para as cucuias depois da goleada dos argentinos sobre os peruanos, aqueles canalhas, miseráveis, sem-vergonha que deveriam ser proibidos de cantar seu hino nacional. Ó, como eu odeio os peruanos! Quando terminou a partida quinta-feira saí babando pelas ruas, caçando os peruanos com a mesma disposição que Wisenthal caça os seus nazistas. Quase peguei um avião e fui apedrejar a Embaixada peruana em Brasília. Cortei relações com meu amigo Mario Vargas Llosa: disse-lhe num telegrama desaforado que só vou voltar a falar com ele no dia que o Peru perdesse de 3 a 0 para a Argentina...

Temos que discutir a atuação desastrosa dos peruanos. O Peru não podia ter perdido de 6 a 0 . Não podia. Perdeu porque é um time antes de tudo individualista, que só pensa nele, sem nehuma solidariedade amazônica. A seleção do Peru sabia que do lado de cá havia 115 milhões de brasileiros sim senhor, 115 milhões não eram dois nem três - torcendo por eles como se fossem peruanos desde criancinhas. No entanto, o que fez ela? Absolutamente nada. Cubillas andava pelo campo como se procurasse uma medalhinha perdida, Cueto se escondia atrás da bandeira de córner, Munante podendo marcar, chutou de propósito na trave, aquele lateral-esquerdo só podia ser o motorista da delegação disfarçado de jogador, e o goleiro Quiroga, bem quanto a Quiroga, basta dizer que que é argentino de nascimento, embora no jogo com o Brasil, depois do gol do Dirceu, eu chegasse a pensar que era brasileiro...

\footnotetext{
${ }^{7}$ Escritor, cronista dramaturgo, nasceu no Rio de Janeiro em 1940. Formou-se em Direito na Universidade Federal da Bahia e teve diversos ofícios antes de começar sua trajetória nos jornais. Trabalhou primeiro no periódico Última Hora e em 1972 começou sua carreira de destaque no Jornal do Brasil, onde permaneceu por 13 anos. Escreveu diversos livros de contos e romances com um estilo próprio muito bem-humorado e crítico dos hábitos cotidianos.
}

O Brasil mais uma vez foi vítima de um complô internacional. Em 74 me lembro de um coronel da Embratel jurando que perdemos da Holanda porque os holandeses jogaram dopados. Agora foi a vez do Peru: jogou subornado. Sei que jogou. Ouvi um participante da mesa de debates do programa Haroldo de Andrade, da Rádio Globo afirmar que havia seis peruanos na "gaveta". Afirmava com tal convicção que só podia estar com o recibo do "suborno" nas mãos. Dizem também que os peruanos abriram as pernas ao saberem que se impedissem a classificação da Argentina nós não iríamos mostrar nosso reconhecimento. Íamos achar que nos classificamos por nossos próprios méritos. Jamais faríamos uma coisa dessas. Tínhamos plena consciência do importante papel que o Peru desempenhava e, da mesma forma como o condenamos por ter nos alijados, estávamos dispostos a anunciar pelos quatro cantos que "conseguimos a classificação graças a bravura do time peruano".

O que dói nisso tudo é que realmente fizemos uma campanha maravilhosa nesta Copa (JORNAL DO BRASIL, CADERNO B, n. 78, 25 jul. 1978, p. 2).

A extensa citação estabelece no trecho introdutório uma debochada revolta contra os peruanos, ironicamente transformado em "ódio" patriótico devido à eliminação do selecionado brasileiro e a ausência de qualquer sentimento de solidariedade latina com uma suposta torcida pela Argentina na final.

Na segunda parte selecionada o destaque está nas irônicas críticas que são feitas ao desempenho da equipe peruana, sobretudo Cubillas, Cueto e o lateral-esquerdo Roberto Rojas, além de Quiroga, visto as metáforas humorísticas de duplo sentido com o nome do país.

No último trecho, a proclamação de um novo "complô internacional" contra o Brasil, bem como as acusações de "suborno", são recursos interpretativos para debochar sobre a constatação da eliminação da seleção brasileira. O último parágrafo, que se desdobra ainda em diversos trechos, sintetiza a ironia ao afirmar que a dor maior foi saber que o Brasil teria disputado uma ótima Copa do Mundo, obviamente uma ironia, diante da irregular campanha feita pela seleção dirigida por Cláudio Coutinho.

\section{CONSIDERAÇÕES FINAIS}

O presente artigo buscou avaliar o fenômeno peruano no mundial de 1978. Relativo ao Peru, não foi 
possível identificar na literatura acadêmica nenhum paradigma estereotipado do que seria o "estilo de jogo peruano", mas nas representações durante o torneio o termo aparece nos periódicos estudados.

A situação do desempenho da equipe peruana é importante, pois foi uma seleção que iniciou o torneio sob desconfiança no quesito técnico, transformou-se na maior surpresa após a primeira fase e terminou a Copa envolta em polêmicas, visto que influenciou diretamente a definição da equipe sul-americana que disputaria a final.

Não há como provar, no âmbito deste artigo ou mesmo na tese que realizei, o suborno de jogadores ou do técnico peruano, a aliança política entre os governos da Argentina e do Peru, a entrega de toneladas de trigo ou mesmo uma troca de prisioneiros no âmbito da Operação Condor. Afirmar a culpabilidade peruana é algo fora do raio de alcance nesta discussão acadêmica, e quanto a isso, não há como falar da equipe peruana.

Entretanto, no âmbito das representações, o Peru foi ator central em diferentes imagens e estórias do mundial argentino. Chegou a ser considerada por Pelé como a grande representante da escola sul-americana no mundial com seu tradicional "estilo peruano", mas parafraseando o humorista Carlos Eduardo Novaes, acabou representado como time expiatório na posteridade, devido ao enquadramento da memória do torneio.

O Peru que a princípio seria uma seleção que faria apenas figuração, tornou-se uma grande "zebra" no torneio e foi transformada em ícone do suposto estilo sul-americano de jogar futebol após o bom desempenho na primeira fase da competição. Entretanto, devido ao acachapante resultado da partida contra a Argentina, ao longo dos anos a boa seleção peruana que disputou a Copa de 1978 acabou sendo enquadrada como "polêmico" vilão expiatório.

\section{REFERÊNCIAS}

ANDERSON, Benedict. Comunidades Imaginadas: reflexões sobre a origem e difusão dos nacionalismos. São Paulo: Companhia das Letras, 2008.

CABO, Alvaro Vicente do. Argentina 6 x 0 Perú - "A partida mais longa da História das Copas do Mundo" por dois jornalistas memorialistas argentinos. In ROCCO, Ary.
Comunicação e esporte: Copa do Mundo de 2014. São Paulo: Intercom, 2014.

ESLAVA, Jorge. Bien jugado: Letras y passíon en el fútbol peruano. Las patadas de una ilusíon. Lima: Ed. Santillana S.A., 2011.

GOTTA, Ricardo. Fuimos campeones. La dictadura, el Mundial 78 y el mistério del 6 a 0 a Perú. Buenos Aires: Edhasa, 2008.

HOBSBAWN, Eric; RANGER, Terence. A invenção das tradições. São Paulo: Paz e Terra, 1997.

LLONTO, Pablo. La verguenza de todos: el dedo em la llaga del Mundial de 78. Buenos Aires: Asoc. Madres del Plaza de Mayo, 2005.

LLOSA, Mario Vargas. "Una passíon llamada fútbol”. In ESLAVA, Jorge. Bien jugado: Letras y passíon en el fútbol peruano. Las patadas de una ilusíon. Lima. Ed. Santillana, S.A, 2011.

MILLA, Rodolfo. “ Chale, Sotil y el Gran perico Leon. Historias dentro y fuera de la cancha." Lima: Editorial San Marcos, 2014.

POLLACK, Michael. Memória, esquecimento e silêncio. In: Estudos Históricos, v.2, n.3. Rio de Janeiro: FGV, 1989.

RONCAGLIOLO, Santiago. La pena máxima. Lima: Alfaguara; Ed. Santilliana S.A., 2014.

VIDAL, Jaime Pulgar. El clássico: el inicio de una rivalidade. Lima: Grupo Editorial Mesa Redonda, 2014.

\section{FONTES PRIMÁRIAS}

Jornal Clarín: 20 maio a 30 jun. 1978, n. 11.574 a n. 11.613. Jornal do Brasil: $1^{\circ}$ maio a 30 jun. 1978.

Revista El Gráfico: 16 maio a 11 jul. 1978, n. 3058 a n. 3066, além de três edições extras sobre as vitórias argentinas durante a Copa do Mundo.

Revista Placar: 7 abr. a 7 jul. 1978, n. 415 a n. 428. 